\title{
Educação e Imagens na Sociedade do Espetáculo: as pedagogias culturais em questão
}

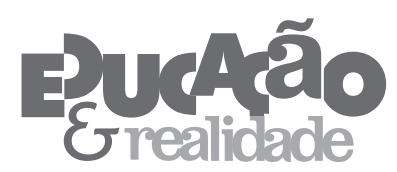

\author{
Alexandre Filordi de Carvalho' \\ 'Universidade Federal de São Paulo (UNIFESP), São Paulo/SP - Brasil
}

\begin{abstract}
RESUMO - Educação e Imagens na Sociedade do Espetáculo: as pedagogias culturais em questão. $\mathrm{O}$ artigo analisa as razões pelos quais a cultura de imagens se faz presente nos agentes simbólicos da atual cultura, fomentando experiências e estratégias educativas que se difundem para além das fronteiras da educação formal. A hipótese é a de que toda análise crítica dirigida às pedagogias culturais viabilizam condições para que as estratégias educacionais também utilizem componentes imagéticos presentes nos agentes simbólicos da cultura. Para tanto, será analisada a cultura das imagens na perspectiva da Sociedade do Espetáculo (2000), e as razões pelas quais a análise crítica das pedagogias culturais se tornam essenciais no campo da educação, desafiando as próprias práticas educacionais atuais. Palavras-chave: Educação. Pedagogias Culturais. Cultura. Sociedade do Espetáculo.
\end{abstract}

\begin{abstract}
Education and Images in the Spectacle Society: cultural pedagogies in question. This article analyzes the reasons why the culture of images is present in the symbolic agents of the current culture, promoting educational experiences and strategies that have disseminate beyond the boundaries of formal education. The hypothesis is based on the idea that the critical analysis oriented to cultural pedagogies promotes conditions that enable the educational strategies through the use of imagetics components present in the agents of symbolic culture. To achieve this goal, it will be necessary to analyze the culture of image through the perspective of the Society of Spectacle (2000), and why the critical analysis of cultural pedagogies become essential in the educational field, challenging the actual educational practices.

Keywords: Education. Cultural Pedagogies. Culture. Society of the Spectacle.
\end{abstract}

Educação \& Realidade, Porto Alegre, v. 38, n. 2, p. 587-602, abr./jun. 2013.

Disponível em: <http://www.ufrgs.br/edu_realidade> 
Educação e Imagens na Sociedade do Espetáculo

O espetáculo não é um conjunto de imagens, mas uma relação social entre pessoas, mediada por imagens (Guy Debord, 2000, p. 14).

Essas imagens [pós-fotográficas] estabelecem com o receptor uma relação quase orgânica, numa interface corpórea e mental imediata, suave e complementar, até o ponto de o receptor não saber mais se é ele que olha para a imagem ou a imagem para ele (Santaella; Nöth, 1999, p. 174-175).

\section{Introdução}

A partir da concepção de que a cultura também se dá como experiência concreta mediada por agentes simbólicos (Geertz, 1989), buscamos priorizar neste artigo, para efeitos de investigação, os aparatos imagéticos da sociedade contemporânea como importantes mediadores nas/das condições pelas quais nos constituímos sujeitos históricos neste contexto. Assim, de modo geral, o nosso objetivo é o de analisar os diferentes modos pelos quais a cultura de imagens se faz presente nos agentes simbólicos de nossa contemporaneidade, fazendo urdir experiências e estratégias educativas que se difundem para além das fronteiras da educação formal.

A nossa hipótese é a de que toda análise crítica dirigida às pedagogias culturais podem urdir condições para que as estratégias educacionais também se valham dos componentes imagéticos, os mais diversos, presentes nos agentes simbólicos de nossa cultura contemporânea. Desta maneira, pensamos que a educação se empodera de condições atuais e práticas para formar leitores agentes da realidade, e nela interventores.

Para tanto, seguiremos dois caminhos. Em uma primeira etapa, trataremos de investigar as razões pelas quais a cultura imagética impregna as nossas experiências atuais de relações sociais. Carregadas de sentidos, de representações simbólicas, de conteúdos representacionais, de informações senso-cognitivas, as imagens adensam-se tramando a possibilidade conceitual e analítica de uma sociedade espetacular. Mais do que uma mera noção debordiana, como veremos, a Sociedade do Espetáculo (2000) nos envolve em uma condição existencial, em que estar na imagem redunda em se encontrar em determinada condição de existência. O que decorre, cabe-nos indagar, no âmbito da formação humana, quando são levadas em consideração as relações entre sujeitos culturais e objetos culturais imagéticos?

Numa segunda senda, demonstraremos que a cultura das imagens representa uma das ações estratégicas fundamentais das pedagogias culturais, pois estas servem como ferramenta de exploração dos mecanismos sociais de valores, de atitudes, de formação de gosto e de seus conteúdos, em nosso caso, perspectivados pela cultura imagéti- 
ca, como condição de investimento na formação de sujeitos sociais e históricos relacionados, de maneira incontornável, com a sociedade do espetáculo. Duas questões cruciais pautarão este empreendimento: seria possível a educação contemporânea ignorar o que representa a relação estética, senso-cognitiva, perceptorial, imaginativa, afetiva e emocional dos agentes culturais quando interagem na e com a cultura das imagens? Não estaria em xeque um tipo de formação sub-reptícia de poderio consideravelmente fetichista, convincente, atraente e que, para além de bem e de mal, acaba por se relacionar com a constituição de sujeitos históricos?

O nosso foco não se constitui em propor caminhos de como as estratégias educativas e as experiências com a educação podem se valer do uso das imagens em seus campos. Restringiremo-nos a um exercício problematizador que leva em consideração a tentativa de nos abrirmos a uma perspectiva que desafia o sentido restrito da educação, e que evoca o esforço para juntos construirmos intervenções ativas em uma cultura que não prescinde mais da imagem para poder relacionar com os seus sujeitos e com os seus objetos culturais.

Cumpre ressaltar ainda que temos consciência que a relação educação e imagens, quer seja no contexto das pesquisas das pedagogias culturais, no campo dos Estudos Culturais, ou das análises das formas simbólicas de nossa cultura, prefigura-se há muito tempo no campo das pesquisas em Educação, como, por exemplo, vemos em Almeida (1994), em Giroux (1995), em Steinberg e Kincheloe (2001), em Fontenelle (2002) e em Silva (2007). Não obstante, pensamos que relacionar a dimensão crítica do pensamento de Debord (2000) com as referências simbólicas de nossa cultura a partir de Geertz (1989), enfatizando a sua dimensão imagética, pode fortalecer o nosso entendimento acerca das estratégias pelas quais as pedagogias culturais se municiam para perpetuar, como veremos, a dimensão espetacular do ser humano.

\section{A Cultura das Imagens em Tempos de Sociedade do Espetáculo}

A cada momento vivido em nossa sociedade presenciamos profundas transformações sociais, em múltiplos e em amplos aspectos, que trazem novas discussões e enfoques para o debate das Ciências Humanas. O posicionamento dos saberes, não importando as suas disciplinas ou categorias, tremula incansavelmente entre a produção de novas tecnologias e novas compreensões que emergem com o intuito de auxiliar o ser humano em suas novas relações com as práticas sociais, culturais e históricas. O mesmo não poderia ser diferente com as experiências educativas.

Segundo Manuel Castells (1999), experimentamos atualmente uma "nova" sociedade em constante formação, pautada por relações temporais e espaciais de rápidas transitividades, interconectadas pela virtualidade e presença momentânea de informações globais, engen-

Educação \& Realidade, Porto Alegre, v. 38, n. 2, p. 587-602, abr./jun. 2013. 589

Disponível em: <http://www.ufrgs.br/edu_realidade> 
Educação e Imagens na Sociedade do Espetáculo

dradas na perspectiva de um sistema de produção capitalista específico. Dentro dessa dinâmica, o autor constrói a ideia de sociedade em rede. Para Castells (1999, p. 498):

\begin{abstract}
[...] redes são instrumentos apropriados para a economia capitalista baseada na inovação, globalização e concentração descentralizada; para o trabalho, trabalhadores e empresas voltadas para a flexibilidade e adaptabilidade; para uma cultura de desconstrução e reconstrução contínuas; para uma política destinada ao processamento instantâneo de novos valores e humores políticos; e para uma organização social que vise a suplementação do espaço e invalidação do tempo.
\end{abstract}

Não há como negarmos que tais constatações, que servem para a definição de sociedade em rede, são vivenciadas por todos nós, embora em distintas formas e intensidades, pois os indivíduos não se relacionam da mesma maneira, com as mesmas demandas, intenções e perspectivas em sua cultura, ou se preferirmos, na rede social. Para exemplificar, podemos pensar em nossa interação com os conjuntos de informações infográficas - textos visuais produzidos pelo tecnicismo informático - presentes nos e-learnings ou nos amplos acessos culturais permitidos pelo ciberespaço e pelas experiências de nossa cultura da imagem.

Seria imprudente, contudo, desprezar que as condições sociais a permitir tal dinâmica na sociedade em rede se deram a partir de uma transmutação de relações históricas baseadas em inovação e descentralização, numa dinâmica cultural de desconstrução e (re)construção contínuas de saberes e de produtos, em um processamento instantâneo de valores agregados a uma transitoriedade cada vez mais intensa. Como sabemos, isto ocorreu, para efeitos históricos, desde a primeira Revolução Capitalista no século XIX, reposicionando os sentidos de atuação e de construção social. No caso contemporâneo, conforme Mészáros (2002) e Fontenelle (2002), as condições que dinamizam e permeiam as relações sociais dizem respeito à conexão direta ou indireta dos indivíduos sociais com uma era do capital volátil, mas, sobretudo, com uma era das relações voláteis, ou seja, instantâneas, ou ainda, espetaculares. Evidenciemos isto de uma forma mais apropriada.

Na obra a Sociedade do Espetáculo, Guy Debord (2000) nos aponta para uma aurora nas transformações em que a sociedade passaria a ter a partir de novas relações sociais e materiais, contidas em recentes formas de produção. Essas novas relações, segundo Debord, têm por base a transformação do capital, notadamente de cunho econômico, para um capital mais reticular, amplo, de fácil dissimulação, baseado e fundamentado naquilo que o autor designou de sociedade do espetáculo, ou sociedade mediada por imagens.

Em seu fragmento de número trinta e quatro, encontramos a seguinte proposição: "O espetáculo é o capital em tal grau de acumulação 
que se torna imagem" (Debord, 2000, p. 25). E como havia anteriormente fundamentado, explica, no quarto fragmento, que “[...] o espetáculo não é um conjunto de imagens, mas uma relação social entre pessoas, mediada por imagens" (2000, p. 14). Logo, diante dessas premissas, indica Debord, a partir da sociedade do espetáculo "tudo que era vivido diretamente tornou-se uma representação” (2000, p. 13).

As representações, capazes de condensar intensas relações sociais estariam, para Debord, presentes em várias fórmulas particulares de atuação das imagens. De certo modo, seriam o meio e o próprio fim de falar de nosso pertencimento a essa época histórica, quer seja através de informação ou propaganda, publicidade ou consumo direto de divertimentos eivados pela indústria cultural, quer seja por intermédio da relação imagem com conteúdo explicitador de enunciados: o vício da presença da imagem como ilustração pedagógica, por exemplo. Não importa, pois o espetacular se constituíra como o modelo atual da vida dominante da sociedade.

Nessa mesma orientação, John Thompson (1999), ao analisar a cultura moderna por intermédio do viés da teoria social crítica na era dos meios de comunicação de massa, ressalta o fato de que "[...] vivemos hoje num mundo em que a circulação generalizada de formas simbólicas desempenha um papel fundamental e sempre crescente [...]" na sociedade, através de "expressões linguísticas, gestos, ações, obras de arte, etc.” (1999, p. 09). Isso diz respeito às infinitas possibilidades de encontrarmos, no que Thompson denomina fórmula simbólica, importantes referenciais como ponto de partida para uma análise cultural.

Poderíamos pensar, desse modo, que aquilo que ganha sentido em Debord para a compreensão da atual sociedade cujo status primordial e representativo é o da imagem como materialização das relações pautadas por um tipo determinado de produção material capitalista, para Thompson, de um modo mais amplo, ganha sentido através de fórmulas simbólicas, definindo em uma dimensão mais específica o locus da imagem, não como a única via para a construção de uma análise cultural, mas como uma das possibilidades contidas nas formas simbólicas. Em ambos os autores, todavia, encontramos a imagem como questão central de partida para a compreensão de nossa sociedade.

Nessa perspectiva, e tomando-a como hipótese plausível, presumimos que a análise de nossos limites históricos também podem se condensar, representativamente, no campo da discussão das imagens. Em outras palavras, as imagens catalisariam o momento histórico em que vivemos, indiferentemente de sua nomeação, pois carregam e sintetizam vários aspectos de nossa inserção e relação cultural a qual pertencemos. Isso nos leva a crer que as imagens, variavelmente distintas em suas formas plásticas, representam a configuração de certo olhar sobre nós mesmos, dizendo daquilo que somos e de onde estamos ${ }^{1}$.

É através desse contexto de relação cultural e imagens que somos convidados a entender a dinâmica histórica presente em nosso instan- 
Educação e Imagens na Sociedade do Espetáculo

te. Para ilustrar melhor tal ponto, a análise de dois exemplos que nos situam em algumas práticas concretas vividas por nós é elucidativa: de um lado, a cultura do consumo e, de outro, o que Almeida (1994) denominou de nova oralidade.

Reportemo-nos novamente a Debord (2000). Para ele, o consumismo está diretamente relacionado com uma cultura de imagens: a mercadoria se transforma em uma ilusão efetivamente real. Apesar do aparente oximoro, revela-se que toda mercadoria, imersa numa relação de imagens, depura e deflagra um consumo que não se pauta pela materialidade efetiva do produto, mas, ao contrário, por sua ilusão de satisfação posta em uma pseudonecessidade. Para o autor, "[...] o consumidor real tornou-se consumidor de ilusões. A mercadoria é essa ilusão efetivamente real, e o espetáculo é sua manifestação total" (Debord, 2000, p. 33). Essa constatação ganha sentido mais relevante ao passo que tanto a mercadoria quanto os sujeitos históricos estão circunscritos a "[...] uma sociedade saturada por signos e mensagens em que tudo se torna mediado pela cultura e na qual tudo são imagens, tudo vem aos nossos olhos com o imediatismo das representações culturais" (Fontenelle, 2002, p. 285).

Ademais, ainda podemos entender algo que nos diz respeito às relações humanas neste contexto amplo da sociedade de imagens ou sociedade espetacular. Trata-se da própria constituição das relações capitalistas. Desde Bourdieu (1998) somos autorizados a poder pensar o quanto que as relações humanas se configuram em uma mútua ação e dinâmica para estruturar a nossa atual sociedade capitalista. Tais relações se perpassam na dimensão de um capital econômico, cultural, social e simbólico. Podemos pensar, com efeito, que vivemos em um limite volátil dessas relações perante uma nova construção e dinâmica de um capital capaz de aglutinar esses vários níveis de atuação e de concentração, transformando-os em um "capitalismo imagético", ao mesmo tempo em que os depura.

Trata-se de um processo de valorização do capital que passa a ocorrer através do trabalho abstrato em sua forma virtual, mediante a produção desterritorializada de informação, a superprodução da indústria do efêmero, do fast thinking e da compreensão instantânea, cujas vigas de sustentação são estruturadas em uma cultura da imagem. Assim, poderíamos pensar, ancorados mais uma vez em Debord, que "a fase atual, em que a vida social está totalmente tomada pelos resultados acumulados da economia, leva a um deslizamento generalizado do ter para o parecer, do qual todo ter efetivo deve extrair seu prestígio imediato e sua função última" (2000, p. 18). Parece-nos, então, que nas mais distintas "economias" de relação capital, quer seja econômico, cultural, social ou simbólico, o parecer alocou-se como fenômeno condicionante das formas destas relações.

Com efeito, no mesmo contexto de cultura e de imagem, poderíamos situar e entender as relações educacionais em um sentido am- 
plo de uma nova cultura educacional que, como indica Almeida (1994), circunscrevem-se a uma nova cultura oral, cuja sustentação promanam das imagens e dos sons.

\begin{abstract}
Dessa nova oralidade compartilham de maneira fundamental as produções de imagens e sons de cinema e principalmente da televisão. Se anteriormente à massificação do cinema e da televisão poderíamos pensar em uma comunidade de pessoas, hoje é forçoso pensar em uma comunidade de espectadores, de consumidores de imagens e de sons, pessoas que formam sua inteligibilidade de mundo a partir das informações dos meios de comunicação de massas, das informações que lhes vêm por imagens e sons, dessa nova oralidade (Almeida, 1994, p. 45, grifos nossos).
\end{abstract}

Ao que tudo indica, há uma evidente relação entre as estratégias de produção e de circulação das imagens na sociedade do espetáculo que se entrelaça com a formação desta comunidade de espectadores e de consumidores que, no limite, somos nós. Os múltiplos elementos cognitivos e sensitivos que emanam deste contexto, como afirma acima Almeida, afeta a própria constituição dos sujeitos, o modo pelo qual eles formam a sua inteligibilidade acerca do mundo e, por suposto, acerca de si mesmos.

Poderíamos, então, forçosamente nos indagar se a educação atual não deveria fomentar leitores, ou melhor, intérpretes ativos e atuantes que construam ações críticas e positivas circunscritas ao aggiornamento desta realidade, permeada pela cultura das imagens, como queremos destacar? Consequentemente não seria uma forma de a educação permitir que os sujeitos indagassem e interviessem nas próprias condições de formação de suas inteligibilidades, como mencionou Almeida?

Ao fazermos essas considerações, partindo dos exemplos do consumismo e da nova oralidade, intentamos demonstrar a importância existente na relação entre cultura e imagem com as experiências educativas. Em outras palavras, buscamos situar o nosso tempo em um contexto amplo cujas relações sociais, dada à nossa própria compreensão de cultura, atrelam-se à dimensão da importância que as imagens têm para as relações humanas. Por conseguinte, também assinalamos para um tipo de modo pelo qual homens e mulheres se relacionam em um determinado percurso histórico para alcançar certa formação e compreensão de si mesmos e de suas visões de mundo. Ressaltamos ainda que as formas pelas quais interagimos e nos relacionamos atualmente com as imagens ganharam um novo sentido e uma dinâmica mais intensa para a nossa formação cultural. Portanto, as imagens assumiram um papel fundamental em nossa constituição humana, e, consequentemente, na configuração de nossas relações culturais e de nossos saberes. 
Educação e Imagens na Sociedade do Espetáculo

\section{Educação e Imagens: interfaces com as pedagogias culturais}

Ao mencionarmos a importância das imagens para as relações culturais, levamos em consideração a compreensão de cultura que, em momento algum, desconsidera a centralidade que as fórmulas simbólicas desempenham para qualquer que seja o seu tipo. Não é à toa que para Geertz (1989) a compreensão cultural se atrela necessariamente a uma série de mecanismos simbólicos. Estes, por sua vez, são nossas construções humanas que, além de dizerem de nós mesmos, de nossa época, valores, ideias e práticas, revelam-nos o modo pelo qual nos concebemos e nos relacionamos dentro de nossa cultura. Para o autor,

[...] o homem, animal que faz ferramentas, que ri ou que mente, é também um animal incompleto - ou mais corretamente, um animal que se completa. Agente de sua própria realização, ele cria a capacidade específica que o define a partir de sua capacidade geral para a construção de modelos simbólicos (Geertz, 1989, p. 189).

A implicação deste apontamento nos coloca em direção da necessidade de relacionarmos a cultura com modelos simbólicos, uma vez que funcionam como mecanismos exosomáticos para a formação daquilo que em boa parte somos: um artefato das relações culturais ${ }^{2}$. Ora, nesta especificidade, a cultura é vista como

[...] um conjunto de símbolos para o controle do comportamento, fontes de informação extra-somáticas, a cultura fornece o vínculo entre o que os homens são intrinsecamente capazes de se tornar e o que eles realmente se tornam, um por um. Tornar-se humano é tornar-se individual, e nós nos tornamos individuais sob a direção dos padrões culturais, sistemas de significados criados historicamente em termos dos quais damos forma, ordem, objetivo e direção às nossas vidas (Geertz, 1989, p. 64).

Por conseguinte, quando nos voltamos para uma análise de uma série de mecanismos simbólicos, deparamo-nos com um sistema de símbolos a representar fontes extrínsecas de informação. Por sua vez, elas se relacionam conosco e podem nos servir como elementos significativos de construção cultural, isto é, do que diz respeito ao nosso pensar, agir, sentir, fazer, desejar, enfim, conceber modos de vida. Daí entendermos o que Geertz chama de "controle humano" não como uma intenção mecânica de querer controlar as pessoas, como se qualquer mecanismo simbólico servisse somente para tal propósito, mas como um gabarito cultural que constantemente fornece a todos nós balizas ou referências para a nossa constituição humana. Nesses termos, “[...] pensar, conceituar, formular, compreender, entender, ou o que quer que seja consiste não em acontecimentos fantasmagóricos na cabeça, mas em combinar os estados e processos dos modelos simbólicos com os estados e processos do mundo mais amplo" (Geertz, 1989, p. 185). 
Ora, levando em consideração que um dos processos de modelos simbólicos mais atuantes na sociedade contemporânea se encontra na produção, difusão e recepção de imagens “[...] na sociedade contemporânea, estar na imagem é existir [...]”, recorda-nos Debord (2000, p. 23), as experiências educativas são convidadas a se posicionarem ativa e criticamente nesse contexto. Pensar uma dimensão educativa no contexto da cultura imagética diz respeito ao conhecimento e ao posicionamento dos sujeitos envolvidos nessa sociedade transmutada em sociedade espetacular, das imagens infográficas, da nova oralidade calcada em uma imagética ubíqua.

Tal dimensão apresenta-se como um vetor de discussão muito sério e consequente no aspecto da educação. Se, como cogitamos, vivemos em um momento social muito específico, preponderantemente visual, de uma cultura das imagens, é inevitável situarmos a importância das considerações acima na relação com a cultura das imagens. Como Debord enfatizou, “[...] a imagem construída e escolhida por outra pessoa se tornou a principal ligação do indivíduo com o mundo” (2000, p. 188). Em outras palavras, as imagens que nos situam numa certa dimensão fenomênica da cultura e de seus aparatos simbólicos, com as quais nos relacionamos direta ou indiretamente, são as imagens que falam de nosso mundo, de nossa cultura, de nossa história e das nossas condições existenciais.

Essa ligação com o mundo, numa dimensão ampla como possibilidade de aprendizado, formação e educação tem sido uma das preocupações nos debates dos Estudos Culturais ${ }^{3}$. Em jogo, encontra-se o aprendizado como relação permanente dentro de um processo paradidático que permite a formação do ser humano como constituição humana via os múltiplos aspectos que envolvem a educação. Neste caso, é preciso atentar para as múltiplas perspectivas que, à revelia das finalidades educativas engendradas em torno de uma política educacional, por exemplo, operam com o poder de veicular ensinamentos sobre valores, atitudes e comportamentos, instrumentalizando os aparatos simbólicos de nossa cultura ${ }^{4}$.

Ora, a inserção da cultura na educação como objeto de estudo, amplia radicalmente o nosso entendimento sobre as experiências educativas. As possibilidades culturais somam-se a uma nova dimensão de educação: experiências com frentes educativas pouco usuais, como, por exemplo, a análise e uso da linguagem pictórica. No caso da cultura imagética, temos de nos atentar para o seu potencial aparato de relação cultural no âmbito das formas simbólicas. Essa dinâmica funciona como um aspecto organizador de saberes, valores, ideias e concepções, muitas vezes ignorados.

É nesse sentido que o sociólogo americano George Ritzer (1999), ao abordar o tema da McUniversity in Posmodern Consumer Society, ressalta o caráter atual das relações educativas em uma dimensão transeducacional (transeducacional). O prefixo latino trans entra na compo- 
Educação e Imagens na Sociedade do Espetáculo

sição desse termo designando um além de, para além de. Sugere assim o termo um tipo de relação educacional que não se situa mais no que é sistematicamente entendido como educacional, ao menos do ponto de vista formal. Presenciamos, cada vez mais, o crescimento de uma era das possibilidades transeducacionais que, como argumenta Ritzer (1999, p. 160) dar-se-á "[...] a partir do momento que a educação estará em todo lugar, a partir de então, tudo será educacional, então, nada mais estará no sentido educacional".

Esse tipo de educação, como analisa Ritzer, estará em toda e em nenhuma parte, ou seja, permeará não mais um locus, como a escola, mas abrangerá uma série de valores e de imagens cujas referências poderão ser encontradas todos os fios da rede social e cultural de nossa época: estará na dimensão das formas simbólicas, no dito e no não-dito. A questão indicia a gênese de um desafio que a educação tem à frente. Como lidar como uma série de conteúdos culturais que sobrecarregam de referências simbólicas, valorativas, conceptuais, afetivas o nosso cotidiano? As experiências educativas formais são confrontadas, neste prisma, por uma força cultural que transpassa a organização dos aparatos culturais a orbitar em torno dos sujeitos históricos. Por isso mesmo, o acesso a contextos de informação distintos assinalam para um sentido mais amplo em que as experiências educativas devem ser vistas com maior cautela e rigor, justamente pelo fato de seus fluxos comunicativos e de sentidos extrapolarem o núcleo de referência formal da educação.

A consciência deste âmbito transeducacional, com efeito, convoca a própria formalidade educacional para se munir de estratégias de poderio de enfrentamento crítico desta mesma cultura. O importante, a saber, é que a cultura imagética na qual estamos eivados carrega uma ampla estratégia e um inesgotável jogo estruturantes de agenciamentos simbólicos e que, portanto, são capazes de materializar determinada perspectiva de experiência com a cultura. Os sujeitos imersos nesta dimensão acabam por se constituir a partir de um conjunto dado de possibilidades simbólicas.

Neste caso, parece que nos encontramos face a face com profundas implicações para os processos de socialização. Se levarmos em consideração o aumento expressivo de informações que circulam por intermédio de todas as possibilidades de configuração de imagens, apreendemos o quanto os fluxos de referências valorativas, conteudinais, de expressões de realizações dos desejos humanos, de constituição de símbolos que intermedeiam as relações sociais foram pulverizados e tomaram conta da cultura contemporânea. Do privatismo do lar assolado pela centralidade imagética da T.V., e atualmente da internet, à locomoção humana bombardeada pela cultura dos outdoors, a imagem faz-se presente numa dimensão fáustica. Não é mais possível ignorar as implicações na formação subjetiva dos agentes históricos dentro deste zeitgeist.

Tomaz Tadeu da Silva (2000) recorda, de modo geral, que a pedagogia cultural diz respeito ao envolvimento de toda e qualquer insti-

596 Educação \& Realidade, Porto Alegre, v. 38, n. 2, p. 587-602, abr./jun. 2013. Disponível em: <http://www.ufrgs.br/edu_realidade> 
tuição ou dispositivo cultural no “[...] processo de transmissão de atitudes e valores, tais como o cinema, a televisão, as revistas, os museus, etc” (Silva, 2000, p. 89). Isto ressoa no que Steinberg e Kincheloe (2001) concebem por pedagogia cultural. Para eles, a pedagogia cultural "[...] enquadra a educação numa forma variada de áreas sociais, incluindo mas não se limitando à escola" (Steinberg; Kincheloe, 2001, p. 14). Não obstante, toda forma de pedagogia cultural compreende que "[...] áreas pedagógicas são aqueles lugares onde o poder é organizado e difundido, incluindo-se bibliotecas, TV, cinemas, jornais, revistas, brinquedos, propagandas, videogames, livros, esportes, etc." (Steinberg; Kincheloe, 2001, p. 14).

Ora, se considerarmos as relações de poder envolvidas na cultura imagética, a partir do contexto das pedagogias culturais, somos incitados a buscar neste elemento da cultura contemporânea aquelas dimensões simbólicas que, direta ou indiretamente, são responsáveis por amalgamar os nossos modos de vinculação com a nossa sociedade. Em outros termos, a pedagogia cultural nos convoca a agir sobre ela, uma vez que uma de suas características essenciais diz respeito à sua emersão do mundo coorporativo, isto é, justamente aquele que enseja as condições de produção capitalista da sociedade de espetáculo. Se "[...] a pedagogia cultural é estruturada por dinâmicas comerciais", como demonstram Steinberg e Kincheloe (2001, p. 15), não podemos ignorar, neste caso, que "[...] padrões de consumo moldados pelo conjunto de propagandas das empresas capacitam as instituições comerciais como professoras do novo milênio" (Steinberg; Kincheloe, 2001, p. 15). Ora, como sabemos que as imagens compõem a parte fundamental das propagandas, não nos demora perceber as suas importâncias no domínio da pedagogização cultural da existência.

É exemplar, nesse sentido, toda série de imagens que nos mergulham numa referência transeducativa. Impregnadas de valores, ideias, visões de mundo, elas nos referenciam em uma dimensão de expectativas nem sempre reais. Ademais, preparam-nos para uma realidade majoritariamente unívoca em seu sentido, em suas estratégias perceptuais e em sua estetização da existência. Como já haviam demonstrado Adorno e Horkheimer (1985), a cultura de massa tem por função precípua instrumentalizar os sentidos. A partir do momento que sons e imagens circulam intensivamente na sociedade, ocupando todo campo perceptual dos indivíduos, um tipo determinado de efeito é derivado dessa dinâmica. Quanto mais nos encontramos ocupados dentro desta cultura menor é a nossa capacidade de olhá-la de modo isento e crítico. Esta é uma forma atual de educar afectus e perceptus dos indivíduos na sociedade contemporânea. O que vem a desafiar a educação, neste sentido, é o descuido com o necessário tratamento crítico, lúcido e ao mesmo tempo intencional referente às possibilidades de trânsito e de disseminação de todas as referências simbólicas negociadas de maneira subreptícia pela cultura de imagens, representante majoritária de um certo tipo de currículo pedagógico cultural.

Educação \& Realidade, Porto Alegre, v. 38, n. 2, p. 587-602, abr./jun. 2013.

Disponível em: <http://www.ufrgs.br/edu_realidade> 
Educação e Imagens na Sociedade do Espetáculo

Em que pese tais termos, as experiências educativas atuais são convidadas a não ignorar o contexto de produção imagética, presentes em nossa cultura, como um texto social capaz de nos dizer sobre as mudanças no status e na forma de agir por intermédio da educação. É nesse sentido que "[...] os estudos culturais se esforçam por examinar a diversidade de práticas e expressões de comunicação, institucionais e artísticas de uma sociedade" (Steinberg; Kincheloe, 2001, p. 15). Portanto, com nos aponta Henry Giroux, os

Estudos Culturais se baseiam na crença de que entramos num período no qual as distinções que separam e enquadram as disciplinas acadêmicas estabelecidas não podem dar conta da grande diversidade de fenômenos culturais e sociais que caracterizam um mundo pós-industrial cada vez mais hibridizado (Giroux, 1995, p. 89).

Daí o motivo do termo texto cultural designar um dado fenômeno cultural, através do qual, podemos ampliar a nossa leitura (compreensão) de mundo, nosso umwelt e, por conseguinte, os modos de intervenção e de transformação nele. Ao fazermos isso balizamos novas práticas de transformação, de inserção e de crítica social. "A pedagogia tornase, neste caso, o terreno através do qual os/as estudantes discutem e questionam, de forma crítica, os diversos discursos e práticas culturais" (Giroux, 1995, p. 88).

\section{Considerações Finais}

É inegável que as imagens se tornaram presença marcante nos mais diversos discursos e práticas culturais contemporâneas. A educação, em suas mais distintas estratégias, não pode mais ignorar ou dar as costas para os aspectos que perpassam essa cultura. Há uma semiótica infográfica ou pós-infográfica que insiste em comunicar direta ou indiretamente uma série de conteúdos simbólicos e representacionais aos sujeitos históricos e sociais.

Se não foi o nosso objetivo levantar estratégias práticas, ou melhor, didáticas e pedagógicas que pudessem se valer das formas imagéticas para se pensar a formação dos sujeitos-alunos na contemporaneidade, por outro lado, nada nos impediu de pensar, num âmbito geral, as implicações ou as tensões existentes entre a constituição dos sujeitos e suas relações com a cultura de imagens.

De nossa parte, sustentamos que a inserção de um conhecimento ativo voltado para a sociedade do espetáculo e para a análise de nossa constituição histórica, a partir de uma cultura cujas relações humanas são intermediadas o tempo todo por imagens, podem e devem estar presentes. Utilizar todo tipo de informação imagética para a tessitura de um saber que se relaciona com as questões culturais de nossa época é encarar a inevitabilidade do rosto de nossa cultura. É procurar os caminhos que nos incitam a uma crítica do que somos e fazemos, por- 
tanto, é nos empenhar numa constante avaliação histórica de nossa inserção no tempo e no espaço sociocultural de nossa época.

Cada vez que um aluno percorre o seu trecho cotidiano para acessar à sua escola, ele se depara com um número razoável de conteúdos simbólicos expressos em imagens. Se a cada um fosse dado o desafio de levantar o número de imagens com as quais interagem neste percurso; registrar as ideias, os valores, os conteúdos, as tramas e projeções de sucesso e fracasso social presentes em cada imagem; captar o que cada uma delas mais explora - seus temas, suas coincidências, suas dissonâncias; perceber no sentido de ver a imagem a presença social nelas implicadas, um grande passo seria dado para se criar na educação um espaço para que os sujeitos sociais se percebam implicados e ativados nesta cultura de imagens.

As pedagogias culturais, neste sentido, pretendem não apenas desafiar os saberes que se voltam para a formação do ser humana. Elas também convocam a nossa sensibilidade para enxergar nos aparatos simbólicos culturais estratégias que acabam por referenciar algum tipo de condição formativa de valores, de percepções, de juízos, de atitudes e de relações humanas nos sujeitos históricos. Ao mesmo tempo, elas desafiam os sujeitos em formação a tomar consciência de que este mesmo aparato cultural faz girar uma roda histórica da qual eles fazem parte, ativa ou passivamente. Ativar os sujeitos sociais por intermédio da educação não é apenas um trabalho de formação de consciência crítica, mas implica uma formação de agentes sociais ativos, integrados a uma cultura preponderantemente marcada pela intensidade da homogeneização. Em outros termos, a educação conclama para si a responsabilidade de uma educação estética do ser humano, por meio da qual, ela possa se posicionar e agir em meio a tais condições estetizantes.

Como se isto não bastasse, Ritzer (1999) chama a atenção para o perigo que a educação corre de fazer de instrumentos pretensamente educacionais um entretenimento. É preciso considerar que boa parte das escolas se vale, não por má-fé, de estratégias "inovadoras" para enriquecer a formação dos alunos: visitas aos parques (não importando os tipos), aos museus, aos cinemas, aos teatros, às mostras culturais, aos mais variados aparatos culturais, o uso da linguagem midiática, para nos valemos de apenas alguns exemplos. Mas entre um percurso e outro, entre um contexto e outro, em meio a um mergulho num mundo das imagens, qual a intensidade de imagens nas quais os alunos são imersos ou entram em contato? Se é correto pensar que "[...] cada manifestação da indústria cultural reproduz as pessoas tais como as modelou a indústria em seu todo" (Adorno; Horkheimer, 1985, p. 119), não podemos ignorar que muitas vezes está em jogo uma mera reprodução de um sistema cultural que avança na redução de nossas capacidades perceptivas com intuito de interpretar, de agir e de modificar esta mesma indústria cultural e a nossa própria cultura.

Educação \& Realidade, Porto Alegre, v. 38, n. 2, p. 587-602, abr./jun. 2013. 
De todo modo, neste caso, o fato de que as imagens são produções e produtoras de uma dada cultura convoca o campo da educação a rever a sua relação com a tal cultura. Nesse caso, a educação não pode fugir deste enfrentamento, pois ela também é um construto cultural e uma construtora da cultura. Estamos em uma cultura preponderantemente imagética, por conseguinte, a educação não se exclui dessa cultura, ao contrário, a ela se relaciona e dela diz respeito, numa dinâmica inseparável.

A partir disso estaremos, como educadores, criando condições para que os educandos sejam alfabetizados nos novos processos culturais-imagéticos nos quais a educação também se dá. Não podemos fugir dessa inevitabilidade e nem negá-la. Nenhuma crítica contribui para a formação do ser humano se por acaso ela nega o que pretende como crítica. Não podemos negar o poder das imagens em nossa cultura. Assim, a educação deve construir leitores capazes de entender o modo pelo qual são construídos e formados, dentro desse intenso processo social existente em nossa cultura de imagens; permitir que eles saibam das consequências existentes nessa cultura e de como podem se relacionar ativamente com essa linguagem, com tudo que ela implica como organizador social.

Assim, devemos permitir que essa prática pedagógica imiscuída nos agentes simbólicos de nossa cultura seja vista como "uma prática histórica e contingente, ativamente envolvida na produção, organização e circulação de textos e poderes institucionais” (Giroux, 1995, p. 95), que nos dizem dos modos pelos quais somos construídos e transformados. Ou dito de outra maneira, "[...] o estudo das imagens [...] da sociedade moderna pode ser um momento para a educação fazer-se cultura, e talvez, poder" (Almeida, 1994, p. 50).

Por esses motivos não podemos dissociar a educação de todas as nossas construções acerca das imagens. A educação, neste caso, é impelida a pensar as relações existentes entre a cultura imagética e as pedagogias culturais, enquanto um agente problematizador de nossas formas simbólicas culturais. As imagens estão na cultura, outrossim, são também da cultura; dizem dela; estão em nós, somos nós e dizem de nós. Portanto, no mundo contemporâneo, a educação estaria para a imagem assim como a imagem estaria para a educação.

Entretanto, como trabalharemos esse campo? Como ele se delimita? A que objetivo pretende? Como chegaremos a esse objetivo e por quê? São questões que precisam ser articuladas com as experiências educativas que cada um de nós é responsável por fazer. Buscar enfrentar esse desafio é buscar respostas inacabadas para a nossa cultura encharcada de imagens. 


\section{Notas}

1 Não ignoramos, como bem indicaram Santaella e Nöth (1999, p. 13), que as “[...] imagens têm sido meios de expressões da cultura humana desde as pinturas pré-históricas das cavernas, milênios antes do aparecimento do registro da palavra pela escrita". O que destacamos, é que as condições atuais de tratamento cultural das/com as imagens diz respeito à forma pós-infográfica, ou imagens de síntese: “[...] trata-se de uma imagem-matriz, resultante da atribuição das propriedades e capacidades de um modelo e cujo abstrato simbólico lhe dá o poder de funcionar como imagem-experimento, antecipando-se ao mundo para melhor controlá-lo" (Santaella; Nöth 1999, p. 171). Na sociedade do espetáculo as relações culturais e sociais são permeadas pelas imagens de síntese, produzindo uma diferença crucial entre um tipo de imagem meramente artística ou artesanal: "Enquanto as imagens artesanais resultam de um gesto idílico, fruto de uma simpatia ou de seu oposto, a agressividade, em relação ao mundo, as imagens fotográficas decorrem de uma espécie de rapto, captura, roubo do real, por trás do qual se insinua um ato não destituído de uma certa perversidade. As imagens de síntese, por seu lado, resultam da necessidade de agir sobre o real, necessidade esta atingida pela mediação de interações lógicas e abstratas com o computador" (Santaella; Nöth, 1999, p. 170, grifos nossos).

2 Obviamente não queremos assumir uma postura beligerante que nega as estruturas ontogenéticas presentes nos seres humanos. Este não é o ponto. A questão está em evidenciar que a cultura contribui certamente para a configuração daquilo que somos. Dizer isto não é negar aquilo outro; um fator não se sobrepõe ao outro e nem o anula, ambos se justapõem em uma dinâmica constante. Como o artigo enfatiza a questão da imagem em nossa cultura relacionada à educação, é notório que concentraremos a questão no ponto da cultura e não ao contrário. Uma pesquisa recente e relevante acerca da relação direta entre condições ontogenéticas e constituição exosomáticas - culturaldo ser humano pode ser verificada em Jean-Marie Schaeffer (2007).

3 Entendemos por Estudos Culturais a interface da educação com as questões culturais que extrapolam as fronteiras acadêmicas. Autores como Henry Giroux (1995), Joe Kincheloe e Shirley Steinberg (2001) são exemplares nesse sentido. Como bem explicita Tomaz Tadeu da Silva (2007), “[...] o que caracteriza a cena social e cultural contemporânea é precisamente o apagamento das fronteiras entre instituições e esferas anteriormente consideradas como distintas e separadas. Revoluções nos sistemas de informação e comunicação, como a Internet, por exemplo, tornam cada vez mais problemáticas as separações e distinções entre o conhecimento cotidiano, o conhecimento da cultura de massa e o conhecimento escolar. É essa permeabilidade que é enfatizada pela perspectiva dos Estudos Culturais" (Silva, 2007, p. 141-142, grifos nossos).

4 Bons exemplos, neste caso, podem ser encontrados em Ariès (1997), em seu estudo denominado Les Fils de McDo: la McDonaldisation du Monde; em Fontenelle (2002), na obra O nome da Marca: McDonald's, fetichismo e cultura descartável; também em Carvalho (2002), na pesquisa Para Além dos Arcos Dourados: a pedagogia cultural do McDonald's; e em Ritzer (1998) por intermédio de sua obra The McDonaldization Thesis. Apesar de suas distintas perspectivas, todas elas avaliam, de uma forma ou de outra, a empresa McDonald's como nicho produtor, divulgador e aplicador de uma ampla gama de aparatos simbólicos carregados de formas de ensinamentos, preceitos e conteúdos informativos visando os mais distintos objetivos.

Educação \& Realidade, Porto Alegre, v. 38, n. 2, p. 587-602, abr./jun. 2013. 


\section{Referências}

ADORNO, Theodor Wiesengrund; HORKHEIMER, Max. Dialética do Esclarecimento. Rio de Janeiro: Jorge Zahar, 1985.

ALMEIDA, Milton. José de. Imagens e Sons: a nova cultura oral. São Paulo: Cortez, 1994.

ÀRIES, Paul.Les Fils de McDo: La McDonalisation du Monde. Paris: L'Harmattan, 1997.

BOURDIEU, Pierre. O Poder Simbólico. Rio de Janeiro: Bertrand Brasil, 1998.

BRADY, Jeanne. Multiculturalismo e o Sonho Americano. In: KINCHELOE, Joe; STEINBERG, Shirley. Cultura Infantil: a construção corporativa da infância. Rio de Janeiro: Civilização Brasileira, 2001. P. 341-352.

CARVALHO, Alexandre Filordi de. Para Além dos Arcos Dourados: a pedagogia cultural do McDonalds. 2002. 130 p. Dissertação (Mestrado em Educação) - Faculdade de Educação, Universidade Estadual de Campinas, Campinas, 2002.

CASTELLS, Manuel. A Sociedade em Rede: a era da informação - economia, sociedade e cultura. São Paulo: Paz e Terra, 1999.

DEBORD, Guy. A Sociedade do Espetáculo. Rio de Janeiro: Contraponto, 2000.

FONTENELLE, Isleide A. O Nome da Marca: McDonald's, fetichismo e cultura do descartável. São Paulo: Boitempo Editorial, 2002.

GEERTZ, Clifford. A Interpretação das Culturas. Rio de Janeiro: LCT, 1989.

GIROUX, Henry. Estudos Culturais nas Faculdades de Educação. In: SILVA, Tomaz T. Alienígenas na Sala de Aula. Porto Alegre: Artes Médicas, 1995.

KINCHELOE, Joe; STEINBERG, Shirley. Cultura Infantil: a construção corporativa da infância. Rio de Janeiro: Civilização Brasileira, 2001.

MÉSZÁROS, Itsván. Para Além do Capital. São Paulo: Boitempo, 2002.

MICELI, Sergio. Imagens Negociadas. São Paulo: Companhia das Letras, 1996. RITZER, George. The McDonaldization Thesis. London: Sage, 1999.

SANTAELLA, Lucia; NÖTH, Winfried. Imagem: cognição, semiótica, mídia. São Paulo: Iluminuras, 1999.

SCHAEFFER, Jean-Marie. La Fin de L'Exception humaine. Paris: Gallimard, 2007.

SILVA, Tomaz Tadeu da. Documentos de Identidade: uma introdução às teorias do currículo. Belo Horizonte: Autêntica, 2007.

SILVA, Tomaz Tadeu da. Teoria Cultural e Educação: um vocabulário crítico. Belo Horizonte: Autêntica, 2000.

THOMPSON, John. Ideologia e Cultura Moderna. Petrópolis: Vozes; 1999.

Alexandre Filordi de Carvalho é professor de Filosofia de Educação no Departamento de Educação da Universidade Federal de São Paulo (UNIFESP), São Paulo.

E-mail: filordi.carvalho@unifesp.br 